\title{
EL TRABAJO EN BENEFICIO DE LA COMUNIDAD COMO ALTERNATIVA A LA PRISIÓN Entre la aceptación y el rechazo
}

\author{
WORKING IN BENEFIT OF COMMUNITY SERVICES AS PRISON \\ ALTERNATIVE \\ Between Acceptance and Rebuff
}

\author{
Joaquín Juan Albalate \\ Universidad de Barcelona, España \\ jjuana@ub.edu
}

\section{RESUMEN}

El debate sobre las medidas alternativas a la prisión y, en particular, sobre el trabajo en beneficio de la comunidad, ha adquirido un renovado interés durante los últimos años, a raíz del progresivo aumento de la población reclusa española. Partiendo de las diversas teorías que existen sobre la pena, se pretende mostrar que, tras más de diez años de haberse aprobado el Código penal vigente, esa medida, aunque ha experimentado recientemente una notable expansión, sigue sin alcanzar su máximo desarrollo, a pesar de los efectos positivos ya demostrados en otros países de nuestro entorno, en cuanto a su mayor eficacia en la reinserción social de las personas encausadas y, por consiguiente, en la disminución de la densidad carcelaria.

\section{Palabras Clave Adicionales}

Pena, Rehabilitación, Reinserción, Política social

\begin{abstract}
As a result of the progressive increase of the imprisoned population in Spain, the debate about alternative measures to prison and, particularly, about the one which proposes working in benefit of community services, has acquired a renewed interest during the last years. Starting from the existing theories about the penalty, the purpose is to show that after more than ten years of the present Penal code approval, although having lately experienced an outstanding expansion, such measure has not yet reached its maximum development. And that in spite of the positive effects already demonstrated in other different countries of our environment in regard to its major efficacy in the social reinsertion of the prosecuted people and, consequently, in the diminution of the prison occupancy density.
\end{abstract}

\section{Additional KeYWords}

Penalty, Rehabilitation, Reinsertion, Social Policy 


\section{INTRODUCCIÓN}

Dentro del ámbito de las políticas sociales relacionadas con la prevención de la delincuencia existe todo un abanico de medidas, encaminadas a la reeducación y reinserción social de las personas recluidas en centros penitenciarios, todas ellas, amparadas por mandato constitucional (Título II, Sección 1. ${ }^{a}$, Artículo 25.2), y, por tanto, de obligado cumplimiento para estos centros. Sin embargo, la demostrada inoperancia continuada del modelo carcelario actual para lograr esos dos objetivos, no ha resuelto el problema de fondo: qué hacer con los individuos que cometen actos delictivos.

Es con ese motivo que aparecieron los primeros debates sobre las alternativas al modelo de prisión clásica en el XII Congreso Penal y Penitenciario de la Haya en 1950, del cual se acabaría derivando, tras largos años de dudas e incertidumbres de las autoridades franquistas, la introducción del régimen abierto en el sistema penitenciario español en 1968.

Desde que se abrió en 1950 la posibilidad del régimen abierto, se han producido importantes cambios legislativos que han afectado al sistema jurídico penal y a las propias instituciones penitenciarias de la mayor parte de los países occidentales, creándose nuevas formas alternativas de sancionar algunos de los delitos, mediante la aplicación de penas sustitutivas o alternativas a la prisión clásica.

Antes de entrar de lleno en las alternativas a la prisión y, en concreto en el tema del "trabajo en beneficio de la comunidad" (a partir de ahora TBC), es necesario hacer una breve referencia histórica a las principales teorías de la pena, para conocer la trayectoria que ha seguido la filosofía conceptual en la que se han sustentado los diversos tipos de penas aplicadas, para luego poder entender mejor el contexto socio-jurídico en el cual surgirá el TBC.

\section{LAS TEORÍAS SOBRE LA PENA}

Desde la aparición de las primeras sociedades organizadas, han existido mecanismos de sanción y coacción sobre los comportamientos considerados por éstas como desviados de la "norma", es decir, apartados de aquellas conductas que la mayoría de esas sociedades entendía que se debían de seguir en el desarrollo de la vida social cotidiana. Desde entonces, una parte de dichas conductas -generalmente, las percibidas por esa mayoría como las más rechazables o peligrosas- se han ido compilando y formalizando en Códigos legales ratificados por los respectivos Estados, asociándolas a unas determinadas penas.

Es evidente que la pena, como cualquier otro fenómeno social universal, ha sido objeto de muy diversas definiciones y calificaciones, según ha sido la función que cada sociedad le ha asignado en cada momento y lugar. No obstante, desde que rige la concepción moderna del Estado, la pena viene siendo considerada como un mal (Sanz, 2000: 34). 
Un mal por la privación o restricción de bienes o derechos jurídicos que aquélla siempre implica. Pero también un mal necesario, porque el principio de legalidad -es decir, el que sustenta que no hay delito y, por tanto, pena, si no hay ley que lo tipifique (Roxin, 1999: 137)- permite recurrir a ella para evitar males mayores que puedan poner en peligro el bien común. Y ello a pesar de que -y ya con el Estado social y democrático de derechoese mal tenga por objetivo principal la prevención de nuevas conductas delictivas, más que afligir o torturar al delincuente condenado, como sucedía en épocas anteriores.

Lo cierto es que la doctrina filosófica-penal no siempre ha imaginado a la pena como el mejor instrumento para prevenir el delito. De hecho, los intentos de legitimar la finalidad de la pena se han concentrado, históricamente, al lado de dos grandes visiones teóricas: las abolicionistas y las justificacionistas (donde se incluyen las preventivas, en sus diversas modalidades, y las eclécticas o mixtas), con posiciones claramente divergentes respecto a esa finalidad y sobre la pena en sí misma.

Pues bien, las principales teorías sobre la pena pueden resumirse en la Tabla 1 de la página siguiente.

El abolicionismo pone en cuestión el supuesto igualitarismo y neutralidad del sistema de justicia penal. Lo consideran, pura y llanamente, una pieza más del engranaje del orden social capitalista, con el cual se legitima y refuerza la desigualdad social y la injusticia. Por todo ello, proponen la desaparición de ese sistema y de todas las normas formales penales, y su sustitución por otros medios de control informal, que permitan devolver el conflicto a sus legítimos protagonistas, es decir, a la víctima y al infractor, para que sean ellos, y no el Estado, los que, en el marco de la comunidad de pertenencia, aprendan a negociar y resolver por sí solos las situaciones de conflicto.

Frente a las posiciones abolicionistas, ha existido y sigue existiendo toda una gama de escuelas que consideran "justificada" la existencia de la pena. Aun a riesgo de simplificar, se puede apuntar que todas las escuelas "justificacionistas" (el retribucionismo o teorías absolutas, la prevención general y especial o teorías relativas, y el eclecticismo o teorías mixtas), aunque comparten la necesidad de la pena para castigar el delito o corregir al delincuente, difieren en el fin que se persigue con la pena.

Para las teorías absolutas -inspiradas en la filosofía idealista de Kant y Hegel de finales del siglo XVIII y principios del XIX, respectivamente- el único fin de la pena es el meramente represivo (Roxin, 1976: 12): el delincuente ha de pagar por el daño que ha cometido a la sociedad (ha de retribuirle, de ahí lo de retribucionismo), por lo que la pena no persigue cambio alguno en la conducta del delincuente -puesto que el delincuente lo es por naturaleza- sino su castigo y aislamiento ilimitado hasta su muerte.

Por su parte, el carácter relativo de la pena en las teorías preventivas, tanto en su versión general como especial, aparece con la llustración (Ferrajoli, 1997: 257). Con ella, el Derecho deja de confundirse con la Moral, el poder deja de percibirse socialmente como "divino", por lo que el Estado será, a partir de ahora, el único que administrará, en nombre del pueblo y no de Dios, la justicia (Sanz, 2000: 50).

La prevención general tiene por objeto impedir que aparezcan nuevos actos delictivos. Y lo hace, mediante los efectos intimidatorios e inhibidores que provoca el mero conoci- 


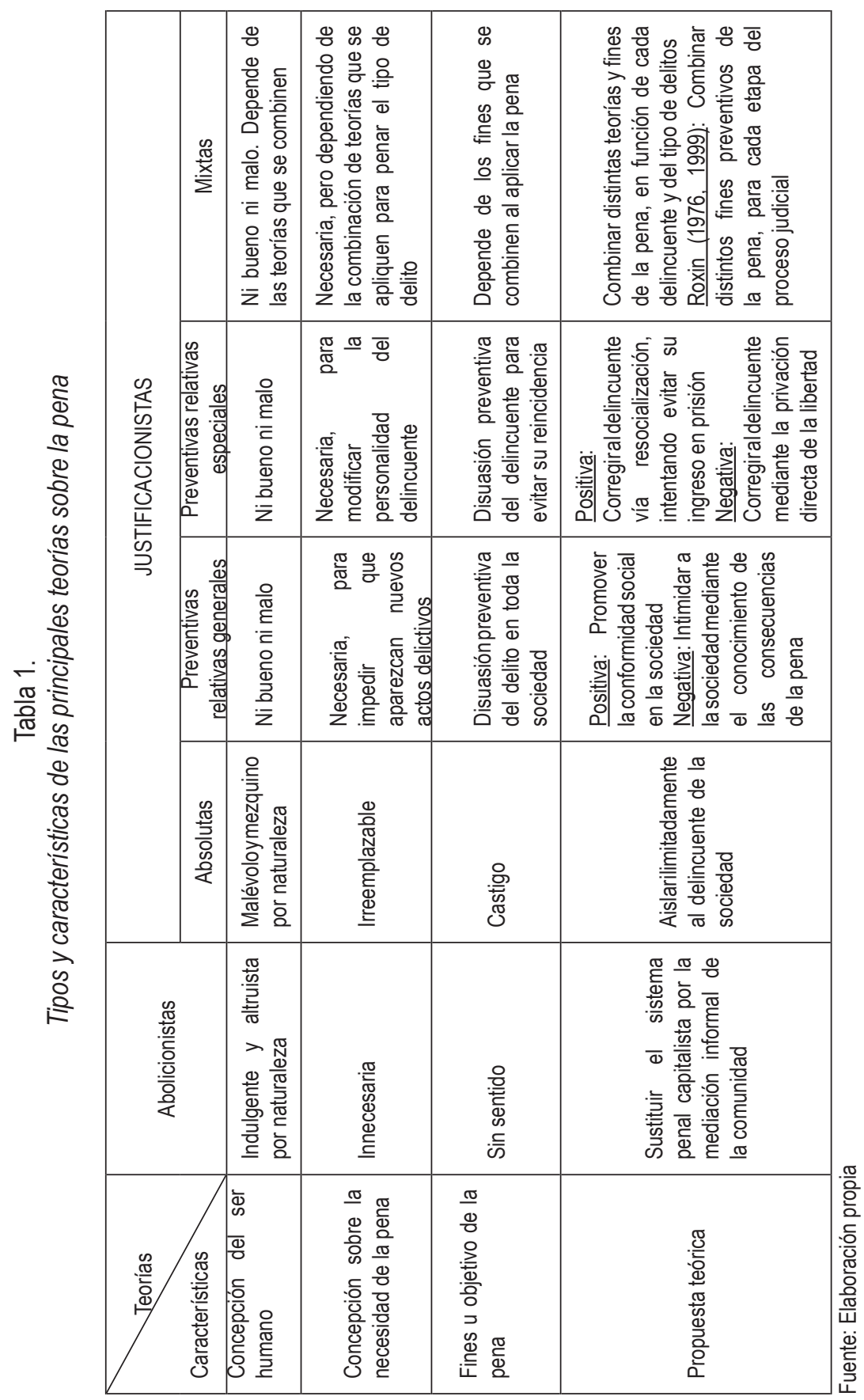


miento, figurado o real, de las consecuencias de la propia pena, tanto en aquellos que vacilan en transgredir la norma, como en los que, sin dudar de ésta, necesitan reconocerse dentro de los límites de la conformidad legal para reforzar su condición de "normales".

Para la prevención general, la pena deja de ser un fin en sí misma (el castigo), para convertirse en un medio de disuasión del delito en toda la sociedad. Dentro de la prevención general se distinguen dos opciones: puede ser positiva o, por el contrario, negativa. La prevención general positiva intenta evitar la comisión de nuevos delitos, mediante la promoción de la conformidad social con las normas formales entre los ciudadanos, para lo cual utiliza la pena como un instrumento de resocialización e integración en la comunidad (Ferrajoli, 1997: 275), siendo la intimidación un recurso secundario.

Se trata de una teoría funcionalista que observa el delito como una disfunción que pone en peligro la estabilidad del sistema político-social, por lo que la pena tiene la misión de restaurar el equilibrio y la confianza de la población hacia ese sistema. La pena expresa la reacción social contra el infractor, constituyendo la réplica de la sociedad al cuestionamiento de las normas y el orden social vigente (Jackobson, 1995: 13).

Por su lado, para demostrar al delincuente que el delito no le compensa, la prevención general negativa parte de una concepción conductista, de tipo culpa-castigo, reduciendo el Derecho penal y la propia pena a la mera función de intimidación. No obstante, aunque coyunturalmente pueda reducir la probabilidad del delito -en particular, cuando la prevención general positiva ha demostrado ser incapaz de lograrlo por la vía de la integración y el control social- siempre se trata de una opción penal de máximos, a menudo, ineficaz.

Y eso es así, por dos razones. En primer lugar, porque busca la disuasión de la delincuencia a través de la coacción ejemplarizante que ejerce la severidad de la pena en la población. Y como ya se ha demostrado empíricamente, los efectos intimidatorios que se desprenden del conocimiento de la pena -por grave que ésta sea (caso de la pena de muerte en EE.UU y otros países, por ejemplo)-solo actúan como continentes del impulso delictivo en una proporción pequeña de la población potencialmente delincuente.

Pero sobre todo y, en segundo lugar, porque, por encima de que consiga o no la reducción futura de nuevos delitos; dado que los efectos intimidatorios que se persiguen suelen ser más factibles de alcanzar, conforme mayor y más severas son las penas; la supuesta protección contra la potencial discrecionalidad del Estado, puede derivar en arbitrariedad por parte de quienes crean, interpretan y aplican la ley (Ferrajoli, 1997: 277), de modo que, en el caso más extremo -por ejemplo, en Estados autoritarios- la intimidación se puede convertir en un auténtico "terror" penal (Sanz, 2000: 57).

De otro lado, están las teorías relativas y la prevención especial. La prevención especial parte de la premisa de que la seguridad pública no sólo se alcanza a través de las actuaciones genéricas o abstractas que proceden de la prevención general, sino también de actuar directamente en la personalidad del individuo que delinque (Sanz, 2000: 72). En este sentido, la prevención especial justifica la pena con el fin de prevenir la reincidencia de quien ya ha cometido el delito, y no tanto para que actúe de amenaza abstracta para el conjunto de la sociedad.

Además, de igual modo que con la prevención general, la prevención especial puede ser positiva o negativa. Se entiende como positiva cuando lo que se persigue es 
la corrección del delincuente, mediante la resocialización. Por el contrario, se entiende como negativa cuando se actúa sobre el individuo para, directamente, privarle de libertad; aunque a veces eso sea fruto de un fracaso previo por la vía positiva.

Por último, cabe hablar de las llamadas teorías eclécticas o mixtas. Estas teorías defienden, a diferencia de las anteriores, que la pena ha de compatibilizar diversos fines -y no únicamente uno- debido a la insostenibilidad jurídica en solitario de cualquiera de ellos por su cuenta (Jackobs, 1995: 34). En este sentido, mientras unas teorías buscan dicha compatibilidad mediante la agregación de fines que son eminentemente represivos (propios del retribucionismo) con otros que son de utilidad social o individual (propios de las teorías preventivas), otras teorías defienden que tal combinación ha de realizarse, estrictamente, con fines de tipo preventivo.

Contra el carácter meramente "aditivo" de estas teorías, surge la denominada teoría "unificada dialéctica" del alemán Roxin (1976, 1999), la cual no sólo rehuye de conciliar fines que se suman "mecánicamente" en la pena, sino que propugna que la combinación de fines seleccionados, se apliquen, no sólo en la fase de ejecución de la pena -como sucede en los casos precedentes- sino en todas las etapas del proceso de encausamiento (Roxin, 1999: 268).

Su propuesta consiste en aprovechar las ventajas que ofrece la combinación adecuada de los fines de la pena para cada caso concreto, pero aplicándolos a lo largo de cada una de las sucesivas etapas que componen el proceso penal. Es decir, a la etapa de definición y requerimiento de la ley, a la de encausamiento judicial y, por último, a la de ejecución penitenciaria, para asegurar que, desde el principio mismo del proceso judicial, se garantizan los fines previstos para la pena, tanto a ojos de la sociedad, como para el propio individuo encausado.

\section{PRISIÓN ALTERNATIVA Y ALTERNATIVAS A LA PRISIÓN}

Vistas las principales teorías sobre la pena, es el momento de observar cómo se plasman algunas de estas teorías en medidas concretas. En ese sentido, cabe apuntar que las medidas que, actualmente, prevé la legislación vigente son implementadas tanto dentro como fuera de los centros de reclusión. Centrándonos exclusivamente en las que se llevan a cabo, parcial o totalmente, a través del contacto con el exterior de los centros penitenciarios, éstas se pueden clasificar en dos grandes grupos: las que constituyen medidas de "prisión alternativa" o "clásicas", y las que se conforman como "alternativas a la prisión".

Mientras las medidas de "prisión alternativa" se implementan con el propósito de "humanizar" la estancia en la prisión y atenuar los efectos más nocivos de ésta sobre el interno, pero se ejecutan, desde y en contacto con la prisión (Sanz, 2000: 312), en cambio, en las que se conforman como "alternativas a la prisión", la cárcel desaparece como tal -0 , en todo caso, se recurre a ella sólo en situaciones excepcionales- en la medida que resulta innecesaria para cumplir la ejecución de la pena. 
Tabla 2.

Tipos y características de las medidas carcelarias "externas" a la prisión

\begin{tabular}{|c|c|c|}
\hline \multicolumn{2}{|c|}{ Medidas } & Características \\
\hline \multirow[t]{4}{*}{$\begin{array}{l}\text { Prisión } \\
\text { Alternativa }\end{array}$} & $\begin{array}{l}\text { Libertad } \\
\text { vigilada }\end{array}$ & $\begin{array}{l}\text { Objetivos: Atenuar el aislamiento, la desocialización y la } \\
\text { aculturazión que provoca la estancia duradera en la cárcel } \\
\text { Características: } \\
\text { "Semilibertad": Contacto con el exterior (trabajo, familia, } \\
\text { amistades, etc.), previo a la salida de prisión, para aquellos } \\
\text { presos que se encuentran en la fase final de su condena. } \\
\text { "Semidetención": Cumplimiento de toda la pena bajo libertad } \\
\text { vigilada, siempre que la condena no supera los seis meses y no } \\
\text { exista reincidencia u otros agravantes }\end{array}$ \\
\hline & $\begin{array}{l}\text { Arresto fin de } \\
\text { semana }\end{array}$ & $\begin{array}{l}\text { Objetivos: Evitar la desocialización que provoca el ingreso en la } \\
\text { cárcel, si la pena es corta } \\
\text { Características: Contacto con el exterior (familia, amistades, } \\
\text { comunidad, etc.), durante el tiempo de ocio del reo, mediante la } \\
\text { sustitución de la ejecución continuada de la pena en prisión }\end{array}$ \\
\hline & Probation & $\begin{array}{l}\text { Objetivos: Evitar la desocialización que provoca el ingreso en la } \\
\text { cárcel, si la pena es corta } \\
\text { Características:Suspensión de la ejecución de la condena bajo } \\
\text { libertad vigilada a condenados no reincidentes, a condición de } \\
\text { que el individuo observe buena conducta y no reincida }\end{array}$ \\
\hline & Sursis & $\begin{array}{l}\text { Objetivos: Evitar la desocialización que provoca el ingreso en la } \\
\text { cárcel, si la pena es corta } \\
\text { Características: Suspensión de la ejecución de la condena } \\
\text { bajo libertad vigilada a condenados con o sin antecedentes } \\
\text { penales previos, a condición de que el individuo observe buena } \\
\text { conducta y no vuelva a reincidir }\end{array}$ \\
\hline \multirow[t]{2}{*}{$\begin{array}{l}\text { Alternativas } \\
\text { a la } \\
\text { Prisión }\end{array}$} & Multa & $\begin{array}{l}\text { Objetivos: Cumplir la pena eludiendo todo contacto con la } \\
\text { prisión } \\
\text { Características: Pago en efectivo por delitos penales leves no } \\
\text { contemplados antes del nuevo Código Penal de 1995, dirigido a } \\
\text { aquellos individuos que no precisan seguir ningún programa de } \\
\text { reeducación, ni ser objeto de resocialización }\end{array}$ \\
\hline & $\begin{array}{l}\text { Trabajo en } \\
\text { beneficio } \\
\text { comunidad }\end{array}$ & $\begin{array}{l}\text { Objetivos: Cumplir la pena eludiendo todo contacto con la } \\
\text { prisión } \\
\text { Características: Reparación voluntaria del daño cometido por el } \\
\text { delincuente a la comunidad, en términos de trabajo socialmente } \\
\text { útil y no remunerado }\end{array}$ \\
\hline
\end{tabular}

Fuente: Elaboración propia 
Tal como se muestra en la tabla 2, entre las medidas "clásicas" o de prisión alternativa más comunes, cabe destacar, en un primer grupo, a la libertad vigilada bajo palabra (sistema también conocido como parole), y el arresto de "fin de semana". En un segundo grupo, corresponde hablar, sobre todo, de las denominadas probation y sursis, originarias del Reino Unido y Bélgica, respectivamente, y de amplia extensión en otros países.

Por lo que se refiere a las dos medidas del primer grupo, se trata de formas que pretenden atenuar el aislamiento y la desocialización que siempre conlleva la estancia continuada en la prisión, alternándolo con la libertad temporal del preso: bien trabajando fuera de la prisión durante el día, y regresando a ella cada noche, en el primer caso (Munné, 1988: 258), bien regresando a la prisión cada fin de semana, en el segundo.

Respecto a la libertad vigilada bajo palabra o sistema parole, tiene una doble dimensión. Por un lado, existe la denominada "semilibertad", que viene a consistir en una especie de "preparación" de aquellos presos que se encuentran en la fase final de su condena. Por otro lado, existe la denominada "semidetención", que consiste en el cumplimiento de toda la pena bajo libertad vigilada, usualmente utilizado cuando la condena no supera los seis meses.

En cuanto al arresto de "fin de semana" -aparecida ya en el Código penal de 1983 en su Art. 33 y dirigida, especialmente, a reclusos con penas cortas de prisión- se funda en el fraccionamiento de la ejecución de la pena, de forma que se cumpla durante el tiempo de ocio o descanso que el condenado dispone, en términos de arresto localizado en un centro penitenciario, depósito municipal o centro policial, o también en su propio domicilio (en este caso, normalmente, desde primeras horas del sábado a últimas del domingo o primeras del lunes, y siempre que exista la correspondiente vigilancia), con un máximo de 24 fines de semana, y como sustitución de la ejecución de la pena de forma continuada en la prisión. El incumplimiento del arresto en dos ausencias injustificadas, da lugar a la cancelación de esta medida y, como consecuencia, a tener que ejecutar toda la pena impuesta en un principio dentro de la prisión.

Con estas dos medidas -libertad vigilada y arresto de fin de semana- se persigue la rehabilitación del sujeto, mediante el contacto discontinuo con la realidad social externa, en tanto que oportunidad para no perder sus vínculos sociales con sus familiares y el resto de personas de su comunidad y, con ello, poder reestablecer los lazos sociales e iniciar su propia resocialización (Redondo et al. 1997: 30).

Las medidas denominadas probation y sursis, por su parte, aunque también pueden combinar la libertad con la estancia en la prisión, solo lo hacen en los casos más extremos. A pesar de que comparten con la libertad vigilada el hecho de que se asientan en la confianza que la autoridad judicial deposita en el condenado, en cambio, a diferencia de la libertad vigilada -que procede de largas estancias previas en prisión- estas medidas consiguen eludir los traumas de la aculturación que provocan la estancia duradera en la prisión.

En el caso de la probation, se suspende la ejecución de la condena, a condición de que el individuo cumpla una serie de requerimientos cara a su rehabilitación, observando buena conducta durante un tiempo determinado que suele ser superior al tiempo de la 
condena. En el caso de la sursis, la concesión de la libertad se condiciona, igualmente, a que el condenado no vuelva a reincidir, solo que, a diferencia de la probation, aquí el condenado puede tener antecedentes penales.

Por su parte, las medidas alternativas a la prisión se definen por ser, lógicamente, medidas que se ejecutan sin privar -en ningún momento- de libertad al delincuente, para evitar la desvinculación de éste con su comunidad natural. En ese sentido, son medidas que conectan con la corriente teórica desinstitucionalizadora, cuyo principio, más o menos explicitado, presupone que la aparición del delito se debe al ambiente y a la situación familiar, escolar y laboral en la que vive el delincuente (Munné, 1992: 261).

Aunque el abanico de este tipo de medidas es amplio ${ }^{1}$-entre ellas cabe citar la "diversión", el perdón judicial, y todo un conjunto amplio de otras medidas clasificadas, jurídicamente, de "accesorias" (retirada del permiso de conducir, inhabilitación para el ejercicio de un cargo público, etc.); aquí sólo se va a hacer referencia, aunque brevemente, al "pago de una multa", para centrarnos después en "el trabajo en beneficio de la comunidad", por ser las que más se acercan al concepto fidedigno de alternativas a la prisión. Ambas medidas están contempladas para sustituir las penas de privación de libertad no superiores a dos años.

La multa y el trabajo en beneficio de la comunidad están recogidos, principalmente, en los artículos 88 y 89 del nuevo Código penal, publicado en la correspondiente Ley orgánica (BOE, 23-11-1995). En la exposición de motivos de esta ley, se dejaba clara la voluntad del legislador de reformar el sistema penal existente hasta entonces, "... de manera que [la reforma] permita alcanzar, en la medida que sea posible, los objetivos de resocialización que la Constitución le asigna [al sistema penal]...”.

Por lo que respecta a la multa, cabe reseñar que su origen se remonta al Derecho romano, cuando se aplicaba a los individuos que desobedecían reiteradamente a las autoridades. Desde entonces, esta pena ha sufrido numerosos vaivenes, para acabar siendo recuperada en España a principios del siglo XX, tras comprobarse que la privación de libertad en la cárcel no surtía los efectos correctores esperados, a pesar de haber sido tan ensalzados durante el siglo XIX (De León, 1994: 245). Sin embargo, hubo que esperar a que la sociedad alcanzara un cierto nivel de desarrollo socioeconómico, para que una obligación con carácter penal como la multa pudiera tener una aplicación generalizada.

La práctica actual demuestra que se trata de una medida especialmente indicada para reafirmar la existencia de la ley ante personas que no necesitan de resocialización, pero que cometen actos delictivos leves (Sanz, 2000: 319). Para este tipo de delincuentes, se estima que es desproporcionada una pena tan estigmatizadora como la prisión, además de que ésta no ha demostrado que su eficacia para que este tipo de delincuentes renuncien

${ }^{1}$ Según el Código penal de 1995, las medidas alternativas a la prisión pueden proceder de sentencias judiciales de diverso tipo: o bien, de la suspensión, ordinaria o extraordinaria, de la pena, o bien, de la sustitución, ordinaria o extraordinaria, de la ejecución de dicha pena, o bien, de la imposición de medidas de seguridad no privativas de libertad. 
a infringir de nuevo las normas legales. Además, en caso de error judicial, éste se repara con mucha más facilidad cuando se trata de una multa, y tiene menos secuelas para el sujeto que si ese error sucede por la imposición de una pena de prisión.

Ahora bien, este tipo de pena sintoniza claramente con el principio de homo oeconomicus (Dolcini y Paliero, 1989: 158), en el sentido de que el legislador, no sólo parte de la premisa de que, pagando la multa, cabe esperar que el condenado se disuada de cometer nuevos actos delictivos, sino de que es legítimo que éste último quede liberado de toda responsabilidad, al entender que, si paga, ya es suficiente para reparar -no ya a las víctimas, sino a la misma sociedad- de todas las consecuencias que se pudieran derivar de su acto delictivo.

Además, la introducción del dinero como mecanismo para reemplazar a la prisión o a otro tipo de medidas o penas, puede conducir a situaciones de desigualdad de oportunidades ante la ley. Y eso, porque aquellos que disponen de dinero, no sólo pueden hacer frente a la multa con menos problemas que los que no lo disponen, sino porque, por eso mismo, la multa no obra con la misma eficacia preventiva en los que la pueden pagar sin demasiado esfuerzo, que en los que no pueden afrontar su pago.

La prueba de ello es que el principal problema que ha surgido desde su implementación ha sido el de la insolvencia o impago voluntario, o lo que es lo mismo, aun queriendo, el sujeto no puede pagar la deuda. Y ello, a pesar de que la ley prevé que las cuotas periódicas que debe satisfacer el sujeto -los denominados "días-multa" que impone el juez- han de ser proporcionales a sus ingresos netos, y de que éste siempre puede solicitar al tribunal una minoración de la cantidad impuesta, si demuestra que la sanción le puede generar graves perjuicios en sus ingresos para hacer frente a sus cargas personales o familiares.

En todo caso, el impago voluntario, tal como está previsto en el nuevo Código penal, puede dar lugar a un arresto sustitutivo en prisión -aunque, generalmente, en régimen de fin de semana- por tantos días, como días-multa queden por satisfacer, con un mínimo de cinco días y un máximo de dos años, con lo que, en rigor, la prisión, no sólo no actúa como amenaza para quienes no pueden pagar la multa, sino que acaba convirtiéndose en la única opción personas con menos recursos, un remedio que cuestiona, en definitiva, el verdadero carácter de la multa como medida alternativa a la prisión.

\section{EL TRABAJO EN BENEFICIO DE LA COMUNIDAD}

Con relación al trabajo en beneficio de la comunidad - a partir de ahora TBC- cabe empezar diciendo que se trata de una de las medidas alternativas a la pena privativa de libertad que mayor interés ha suscitado en los últimos años en España, por las connotaciones que tiene de reparación directa del daño cometido a la víctima o a la comunidad por parte del delincuente, a pesar de que tal reparación se realice a posteriori, en términos de trabajo revertido. Y eso es algo que, ni la multa, ni la privación de libertad, suelen conseguir.

Pero es que, además, la reparación tiene un doble efecto resocializador para el penado. Por un lado, le obliga a enfrentarse con las consecuencias de sus actos y, por tanto, a 
tener que reconocer los derechos legítimos que tiene las personas por él dañadas, por lo que, en ciertos casos, puede dar lugar a un proceso de reconciliación entre ambas partes y, con ello, a que se puedan abrir las puertas a una posible reintegración del penado en la comunidad (Roxin, 1999: 109). Pero, por otro lado, el mismo hecho de tener que reparar a la víctima o a la sociedad mediante la aportación de su propio trabajo, puede convertirse, igualmente, en una vía para que el penado interiorice de nuevo las normas sociales y, por consiguiente, se pueda reintegrar con mayor facilidad a dicha comunidad.

No obstante, a pesar de su gran difusión en otros países europeos como Francia, Dinamarca, Inglaterra, Holanda, etc., el TBC no ha conocido su regulación explícita en España hasta la aprobación del nuevo Código penal en 1995. Aunque, si bien se ha regulado más tarde, no por ello su aplicación no ha adquirir una gran relevancia. Según la Dirección de Instituciones Penitenciarias, el número de sanciones dictadas de TBC por los jueces en Cataluña, pasaron de ser 681 en 1999, a 3.931 en 2005, mientras que en el resto del Estado español, esas cifras se situaron, para ese mismo período, en 453 y 4.916 , respectivamente. En otras palabras, durante esos últimos seis años -que es cuando mayor impulso ha alcanzado esta medida- este tipo de sanción se ha multiplicado por 5,7 veces en Cataluña, mientras que en el resto del Estado lo ha hecho en 10,8 veces.

Estos resultados han de matizarse, no obstante, ya que buena parte de ese crecimiento se ha producido durante los últimos años, fruto de la modificación del Código penal en noviembre de 2004, por la cual, se otorgó a los jueces la posibilidad de sancionar con esta medida las infracciones de tráfico asociadas a la ingestión de alcohol y, aunque con un impacto numérico menor, a los delitos de violencia de género, a consecuencia de la entrada en vigor de la Ley 1/2004 de medidas de protección integral contra el maltrato familiar.

Es de ese modo, que la trayectoria "natural" de crecimiento del TBC se ha disparado "artificialmente", desvirtuándose con ello, la expansión real que ha seguido el TBC como medida alternativa a la prisión prevista, originariamente, para los delitos de índole penal.

\section{Requisitos y funcionamiento del TBC}

Esta medida, suele prescribirse para sustituir delitos donde la multa aparece como demasiado leve, y la privación de libertad como demasiado grave, por lo que tiende a aplicarse como sustitución de la propia multa, del arresto de fin de semana o, en menor medida, de otras sanciones de gravedad baja o media, cuya pena no supere los dos años (Sanz, 2000: 342, 351).

No obstante, se trata de una medida cuya implementación necesita de unas ciertas garantías. Por un lado, se exige la aceptación previa por parte del penado, tanto del tipo de trabajo que se le propone, como de las condiciones con que lo ha de desarrollar, a fin de evitar eventuales abusos o exigencias que el condenado no esté en condiciones de cumplir. Por otro, el juez puede denegar esta medida si considere que el orden público o la prevención general o especial del detenido pueden quedar dañados. Por ello, casi siempre se excluye de esta sanción a personas alcohólicas, drogadictas, dementes, 
violentas, etc. (Cid et al. 1997: 99), a pesar de que con ello se pueda cometer un cierto trato discriminatorio.

En todo caso, si el condenado no realizara el trabajo en las condiciones acordadas con el juez, o incurriera en alguno de los supuestos que, seguidamente se exponen, sin mediar causa razonable alguna que lo justificase (López Cabrero, 1995: 285), se revocará el TBC, pudiendo el juez dictaminar el arresto domiciliario de fin de semana del sujeto 0 , incluso, su reingreso a la prisión, una vez descontada la parte del tiempo que el penado hubiera cumplido hasta entonces.

Estos supuestos son, de acuerdo con lo reglamentado por el Real Decreto 690/1996, los siguientes:

- Abandono o ausencia del trabajo injustificados. (En caso de baja por incapacidad laboral transitoria, no será considerada causa de incumplimiento, pero no computarán las jornadas perdidas en la liquidación de la condena).

- Desarrollar un rendimiento sensiblemente inferior al mínimo exigible, tras haber sido requerido previamente por el responsable de la entidad o centro de trabajo.

- Oponerse o incumplir de forma reiterada y manifiesta las instrucciones recibidas por el responsable directo de su trabajo.

- Por cualquier otra razón que diera como resultado que el responsable directo de su trabajo se negara a seguir manteniendo al penado en el centro de trabajo.

Por tanto, para evitar que el inculpado incurra en el incumplimiento de alguno de estos supuestos, es muy importante que la actividad sea lo más satisfactoria posible para éste.

Es conveniente, igualmente, que el trabajo tenga la máxima conexión con el delito cometido, a fin de que, a través de él, el sujeto pueda descubrir por sí mismo la dimensión de las consecuencias del acto del que ha sido responsable (Cid et al. 1997: 101). Pero también es oportuno que se realice lo más cerca posible de su entorno social-siempre que la persona lo valore como ventajoso, frente a posibles consecuencias estigmatizadoras-al objeto de potenciar la percepción directa de la reparación de la comunidad, en tanto que respuesta punitiva de ésta.

Por último, es igualmente importante que la actividad sea lo más útil posible para las entidades 0 instituciones sociales a las que se destine el trabajo, de forma que sea la comunidad la que, en última instancia, se acabe beneficiando de dicho trabajo.

\section{El trabajo en beneficio de la comunidad: entre la aceptación y el rechazo}

A pesar de que el TBC ha demostrado un alto potencial de reinserción social en los países donde más aplicación ha tenido (Pares, 1998: 159), ha suscitado reacciones encontradas en la comunidad jurídica y, sobre todo, en la propia sociedad.

Las posiciones favorables al TBC se fundamentan en el carácter regenerador, constructivo y, por tanto, educativo que éste tiene (Redondo et al. 1997: 56), como consecuencia de la transformación que sufre una parte del tiempo libre perdido del penado, en una 
actividad con alta significación social como es el trabajo (Dolcini y Paliero, 1989: 166), sin que por ello esta sanción pierda su carácter disuasivo, sino todo lo contrario, ya que se lleva a cabo sin remuneración y sin reducción alguna de la pena, a diferencia de lo que sucede con otras penas equivalentes. Pues bien, ante estas posiciones se suelen ofrecer las siguientes objeciones:

- La primera de estas objeciones está relacionada con el hecho de que el TBC comporta, como ya se ha dicho, trabajar sin remuneración, por lo que algunos autores lo califican de trabajo forzado (De Solá et al. 1986: 63), (López Cabrero, 1995: 280). Contra esta argumentación se aduce, por un lado, que la ley exige, expresamente, el consentimiento del condenado y que ha de ser él quien solicite la medida. Por otro, aunque no a salario, el culpado tiene derecho a una indemnización por parte de la o las entidades a beneficio de las cuales presta su trabajo, en concepto de gastos de transporte y, en su caso, de manutención, así como de la correspondiente protección social en materia de Seguridad Social y de seguridad y salud laboral.

- En segundo lugar, otra de las alegaciones contra esta medida se refiere a que puede sustraer puestos de trabajo a determinados perfiles ocupacionales, suponiendo una competencia desleal para estas personas, dada la ausencia de remuneración. Ante tales objeciones cabe argüir que las actividades que se desarrollan con el TBC, además de estar concebidas para que no puedan colisionar con el tipo de puestos de trabajo propios de las entidades receptoras del condenado -al actuar aquéllas solo de apoyo y complemento a las que allí se realizan-tienen un carácter, eminentemente voluntario, por lo que, no solo no amenazan el empleo de terceros (López Cabrero, 1995: 281), sino que ocupan ciertos vacíos que el mercado laboral ordinario no es capaz de cubrir.

- Se arguye, también contra el TBC, que el gasto público que se dedica a organizar y atender al penado durante todo el tiempo que se prolonga la pena, podría repercutir negativamente en otras necesidades tan 0 más ineludibles para la sociedad. Frente a ello, se argumenta que, no solo la cárcel, respecto a esta pena, resulta económicamente, mucho más onerosa, sino que los costes para la sociedad, derivados de la obsolescencia o pérdida de hábitos, destrezas o cualificaciones que conllevaría una pena detentiva de igual duración, son igualmente menores (Dolcini, 1977: 480).

- Por último, se argumenta asimismo, que esta pena, al ser una respuesta social que elude la prisión, es demasiado indulgente para una persona que ha sido declarada culpable de un delito castigado con el ingreso en la cárcel. Contra tal afirmación, solo cabe decir que el TBC puede resultar tan o más severo de lo que, aparentemente, pueda parecer para algunas personas. Sobre todo, si se compara con la menor intimidación que suscitan en algunos internos otras penas detentivas equivalentes, que no comportan la pérdida del tiempo de ocio de que disponen en la prisión y 
que, además, dan derecho a reducciones de la pena (Maggini, 1977: 711), algo que, como se ha visto, no sucede con esta medida.

\section{AlgunAS CONCLUSIONES Y PROPUESTAS}

La búsqueda de la reinserción social del recluso es lo que justifica la aplicación del régimen abierto, tanto con medidas de prisión alternativa como, sobre todo, con medidas alternativas a la prisión actual. Sin embargo, en el caso de las primeras, podría suceder que lo que ha aprendido el interno durante su estancia previa en la prisión sea a convivir mejor con las personas y problemas que existen dentro de ella -sobre todo, cuando esa estancia es de cierta duración- comprometiéndose así los efectos positivos de su estancia fuera del recinto penitenciario. Por tanto, que se conceda al individuo el permiso para retornar a la sociedad, provisional o definitivamente, a partir de haber evaluado la evolución positiva de su comportamiento dentro de la prisión, no siempre es garantía suficiente de que esté preparado para vivir de nuevo en su comunidad. Puede que sí, pero puede suceder también que sea aparente.

Si el régimen abierto sigue reproduciendo el mismo ideario, los mismos criterios de funcionamiento y organización internos, las mismas distancias y desconfianzas entre reclusos y funcionarios, etc., que se producen en el régimen cerrado clásico -aunque se lleve a cabo con un margen mayor de libertad de movimientos para los internos- la prisión abierta seguirá (sigue) sin poder hacer realidad el mandato constitucional reeducativo y resocializador de los sujetos condenados, aunque se dignifique la pena

Ahora bien, por mucho que se humanizaran las prisiones, si no se transforma también la sociedad, será difícil que se supriman las contradicciones entre ambas. De nada sirve la prisión abierta, si no se abre a la comunidad y viceversa (Munné, 1992: 264). De hecho, como ya dijera Tönnies, la prisión no es más que una comunidad -y no una asociaciónintegrada dentro de otra comunidad, la sociedad. Pero si la prisión se cierra a la sociedad, no es solo por la dinámica interna que en ella se desarrolla frente a la estigmatización del exterior, sino porque es la sociedad la que, primeramente, la etiqueta de "peligrosa" para protegerse de ella

Por su parte, las principales conclusiones sobre el trabajo en beneficio de la comunidad son las siguientes.

- El TBC no tiene por objeto principal la prestación de un trabajo, sino sustituir la pérdida del tiempo libre de que dispone el condenado, por la ejecución de una actividad útil para la sociedad, aunque no se le remunere por ello (Sanz, 2000: 344). Pero por eso mismo, por no recibir una remuneración, es el desempeño de la propia actividad -y no tanto el resultado del trabajo- lo que ejerce de rehabilitación en el individuo (De Solá et al. 1986: 46).

- Los principales problemas para que el TCB pueda extenderse, provienen, tanto de los propios infractores (Cid et al. 1997: 103), como de sus beneficiarios. A diferencia de lo que sucede con la multa, que puede imponerse sin acuerdo del infractor, esta 
medida necesita de la aprobación previa del condenado (Sanz, 2000: 355), por lo que queda relegada, permanentemente, a un papel sustitutivo. A todo ello se suma que, como los puestos de trabajo que han de desempeñar los reclusos han de ser, eminentemente, públicos o relacionados con la economía social, la oferta laboral potencial resta bastante limitada.

- Además, si no existe una adecuada coordinación entre los tribunales y las diversas Administraciones implicadas, se pude incurrir en errores de desajuste entre individuo y tipo de trabajo a desempeñar. No hay que olvidar que esta sanción se dirige, generalmente, a personas que padecen múltiples problemáticas personales y sociales (Sanz; 2000: 349), y que, por ello, se ha de evitar que la sanción empeore aún más esa situación.

- Las experiencias desarrolladas en otros países demuestran que el éxito del TCB dependerá, fundamentalmente, del interés que se consiga despertar entre las entidades sociales y en la propia comunidad que han de acoger a estas personas (Cid et al. 1997: 104), (Sanz, 2000: 350). Y eso, a su vez, depende, en buena medida, de la capacidad de los técnicos y asistentes sociales para explicar, anticipada y convincentemente, a esas entidades y a la misma población, los beneficios sociales que les puede reportar una medida orientada enteramente a la compensación directa del daño causado. Sólo así, se pueden neutralizar los prejuicios y recelos que, a menudo, se presentan ante la proximidad de personas convictas.

En definitiva, a pesar de los elevados índices de crecimiento registrados recientemente, la relativa novedad del TCB, aún no permiten predecir con suficiente precisión el grado real de aplicación que esta figura tendrá en España en el futuro. No obstante, la estricta limitación legal de esta sanción para operar sólo como sustitutiva del arresto de fin de semana, cuando este aparece como pena principal, o por el impago de una multa, dejan un escaso margen a los jueces para recurrir a ella -por mucho que se haya extendido "artificialmente" con el tráfico rodado- $y$, por tanto, para que se pueda extender como una verdadera alternativa a la prisión.

En este sentido, cabe realizar las siguientes propuestas para que esta medida pueda adquirir una mayor difusión en el futuro:

- Ampliar su uso para penas superiores a dos años -tal como sucede en otros paísessiempre que se pueda garantizar que la gravedad de estas o las características específicas del penado, no van a infundir más alarma social entre la población y, en particular, entre las personas con las que este tome contacto, que la que ya sucede con las penas menos graves.

- Ampliar su uso sustitutivo a otro tipo de delitos castigados con penas distintas a la multa 0 al arresto de fin de semana, dado que estas sanciones se destinan a delitos singulares y poco usuales, en comparación con el resto de delitos que se cometen.

- Elevar la sanción a la categoría de pena principal, para que su aplicación pueda ser independiente, y convertirse así en una pena verdaderamente alternativa a las penas 
privativas de libertad cortas y, con ello, relegar su papel meramente sustitutorio a casos muy específicos.

- Flexibilizar el derecho del condenado a no aceptar el trabajo y el tipo de actividad que se le proponga, a cambio de que éste pueda elegir entre diversas opciones laborales, y no sólo excepcionalmente como dictamina la ley. Con ello, se lograría una mayor identificación y autorresponsabilización para con la actividad a desempeñar y, por tanto, un mayor cumplimiento de esta medida y un efecto resocializador superior.

- Incluir ayuda especializada que facilite el cumplimiento y, como consecuencia, la disminución del quebrantamiento de la medida, para evitar problemas que acentúen la marginación social del penado.

El fin del TBC es el de suplir a la cárcel. Trabajar para la comunidad, no solo acaba redundando en las personas más necesitadas que en ella viven, sino que es el mejor camino para disminuir los prejuicios que hoy existen contra las personas recluidas en prisión. Solo por eso, el TBC habría de merecer de la sociedad un voto de confianza para poderse extender, al menos, tanto como lo ha hecho ya en otros países de nuestro entorno penal y cultural más cercano.

No obstante, para que eso ocurra será necesario que las diversas instancias gubernamentales implicadas pongan todos los medios que se necesitan, pero también -y, quizás lo más importante- que los organismos jurídicos y la propia sociedad tomen partido a favor de una mayor aplicabilidad, confiando en que su función resocializadora es, como mínimo, tan eficaz como lo puede ser la cárcel, en la que, al parecer, la sociedad actual sigue depositando su máxima confianza para lograr ese mismo objetivo.

\section{REFERENCIAS BibLIOGRÁFICAS}

Asúa Batarrita, A. (1984), "El trabajo al servicio de la comunidad como alternativa a otras penas", Estudios de Deusto, XXXII-2, Deusto, Universidad de Deusto.

Ashworth, A. (1995), Sentencing and Criminal Justice, Londres, Butter-worths

Bona Puigvert, R. (1994), "La función rehabilitadota de la pena de privación de libertad: entre el discurso teórico y el fracaso", Perspectiva Social, 34: 57-65.

Bonal, R. (1992), "La comunidad y el régimen abierto", en Santiago Redondo y Vicente Garrido, La intervención educativa en el medio penitenciario, Madrid, Diagrama.

Bonal, R. y J. Costa, (1986), La població reclusa a Catalunya. Dades per a un treball social penitenciari, Barcelona, Departament de Justicia, Generalitat de Catalunya.

Christie, N. (1985), Abolire la pene? Il paradosso del sistema penale, Torino.

Cid Moliné, J. (1997), "El trabajo en beneficio de la comunidad", en Cid, José y Larrauri, Elena (Coor.), Penas alternativas a la prisión, Barcelona, Bosch. 
Conesa, M. (1994), "Delincuencia y medios de comunicación: un matrimonio de conveniencia", Perspectiva Social 34: 35-44.

Cruells, M. y N. Igareda (2005), Mujeres, integración y prisión, Barcelona, Áurea Eds.

De la Cuesta Arzamendi, J. L. (1985), "La sanción de trabajo en provecho de la comunidad", La Ley, 2 : 1067-1075.

De León Villalba, F. J. (1993), "Sustitutivos penales: multa y arresto de fin de semana. Últimas propuestas", Revista Jurídica de Castilla-La Mancha, 19: 243-278.

De Solà Dueñas, Á. et al. (1986), Alternativas a la prisión. Penas sustitutivas y sometimiento a prueba, Barcelona, Promocions Publicacions Universitarias (PPU).

Dolcini, E. (1977), "Laboto libero e controlle sociale: profili comparastitici e político-criminali", Rivista Italiana di Dritto e Procedura Penales (RIDPP): 479 y ss.

Dolcini-Paliero, E. (1989), Il carcere ha alternative? Le sanzioni sustitutive della detenzione breve nell'esperienza europea, Milán, Giuffrè.

Ferrajoli, L. (1997), Derecho y razón. Teoría del galantismo penal, Madrid, Trotta.

Hassemer, W. (1984), Fundamentos del Derecho Penal, Barcelona, Bosch.

(1982), "Fines de la pena en el Derecho penal de orientación científico-social", en MIR PUIG, S., Derecho Penal y Ciencias Sociales, Barcelona, Bellaterra, Universitat Autònoma de Barcelona PPU: 117-139.

Hormazábal Malareé, H. (1995-1996), "Los problemas de legitimación del Derecho penal y la perspectiva abolicionista", Derecho Pena, vol. XXIII 57-58: 199 y ss.

Jakobs, G. (1995), Derecho penal. Parte general. Fundamentos y teorías de la imputación, Madrid, Marcial Pons.

Larrauri Pijoan, E. (1987), "Abolicionismo del Derecho penal: las propuestas del movimiento abolicionista", Política Criminal, n. ${ }^{\circ}$, pp. 95-122.

Lazerges, C. (2000), "La réinsertion, une réalité a facettes multiples", Archives de Politique Criminalle 11: 99-105.

Liwerant, O. S. (2001), "La sortie de prision des jeunes majeurs: quel lien dedans-dededhors? ", Archives de Politique Criminalle 23: 93-105.

López Cabrero, G. (1995), "Penas cortas de prisión. Medidas sustitutivas”, Política Judicial 40: 269-285.

Maggini, A. (1977), "Il lavoro come misura alternativa", Rivista Italiana di Dritto e Procedura Penales (RIDPP): 700 y ss.

Munné, F. (1992), "Una comunidad abierta a la prisión: dialéctica de una relación patológica", en Santiago Redondo y Vicente Garrido, La intervención educativa en el medio penitenciario, Madrid, Diagrama: 249-266. 
Pares Galles, R. (1998), "La nueva pena de trabajos en beneficio de la comunidad", Cuadernos de política criminal 64: 155-166.

Pavarini, M. (1987), "El sistema de Derecho penal entre abolicionismo y reduccionismo", Política Criminal 1: $141-158$.

Redondo, S. et al. (1997), El cost de la justicia penal, Barcelona, Departament de Justicia, Generalitat de Catalunya.

Roxin, C. (1976), Problemas básicos del Derecho, Barcelona, Reus.

(1999), Derecho penal. Parte general, Madrid, Civitas-Thomson.

Sanz Mulas, N. (2000), Alternativas a la pena privativa de libertad, Madrid, COLEX.

Valmaña Ochaita, S. (1990), Sustitutivos penales y proyectos de reforma en el Derecho penal español, Madrid, Secretaría General Técnica, Ministerio de Justicia.

Walter, N. (1980), "La eficacia y la justicia moral de la prevención", Cuadernos de política criminal 11: 129-146.

Young, W. (1979), Community Service Order. The development and use of a new penal measures, Londres, Heinemann. 